\title{
Alison Milne (2020). Mental Health in Later Life: Taking a Lifecourse Approach. Bristol: Policy Press, 360 pp. ISBN 9781447305712 (paperback)
}

\author{
ReVIeWed bY Jane M. Mullins*
}

It has been timely and insightful to review this critical text in light of the coronavirus disease (COVID) pandemic that has profoundly affected the mental health of the most vulnerable in society, including older adults and those living in residential care (Velayudhan et al. 2020). Professor Milne's book draws from a vast source of theory, research and policy documents to explore both mental health and later life through the broad lens of critical gerontology. In doing so, she examines the complexities of mental health, wellbeing and mental illness and successfully challenges the dominant medical nihilistic view that mental illness (with particular reference to depression and dementia) is inevitable as we age. Her major argument throughout the whole text is for mental health in later life to be viewed within the context of lifecourse. Discourses of ageing and mental ill-health are discussed early on in an attempt to add clarity to concepts that have historically been dominated by medicalisation and its negative functionalist perspective. By introducing further concepts of psychological wellbeing and mental health, Milne offers a far broader perspective that mental health is influenced by events, personality and attitudes throughout the 
International Journal of Ageing and Later Life

lifecourse and should be viewed along a continuum from psychological wellbeing through to mental ill health that fluctuates.

Mental health in later life is a comprehensive body of work that challenges previous conceptualisations of "older age" by introducing the term "later life" and successfully dismisses the homogenisation of people based on age. Each chapter builds a coherent and convincing argument to adopt a lifecourse perspective when exploring the complexity of mental health/ill health that avoids viewing older age in isolation. She examines the extent that structural, socio-political, socio-economic and socio-cultural influences impact on a person's mental health and/ or mental ill-health throughout his/her lifecourse. Indirect risks such as age discrimination, exclusion and marginalisation are put under the spotlight and prove very relevant in light of the recent policies of social isolation in care homes. Milne goes on to examine the multiplicity of direct risks to mental health, including gender, ethnicity, loneliness and isolation, and its potential to impact on cognition, including disability, chronic morbidity, abuse and pain. By challenging ageist constructs around productivity and dependence and embracing the lifecourse perspective, professor Milne recommends a policy shift away from social structures towards an individualised biographical and lived experience approach. Social justice and human rights provide the framework for professor Milne's study, which is clearly informed by her social work practice. Here, she goes on to identify the importance of involving the voices of older people within scholarship, research, practice and policy.

What I found particularly interesting was professor Milne's discovery of the contrasting views between scholarship of the "third age" (where sociology of risk and psychological theories of personality, adaptation and successful ageing are explored) and the "fourth age," where negative discourse around decline, poor function and frailty dominates. Therein lies the gap, where a lack of sociological and psychological perspectives allows for the medicalisation of ageing for those previously considered the "oldest old" to dominate (Suzman et al. 1995). She draws from key policy discussions and literature that maintain the prevailing view that people within the "fourth age" are an economic burden within society, and the management of their physical condition is solely considered. Here, 
she recommends that policy, research and practice once again examine ageing within the context of lifecourse.

Professor Milne's inquiry focuses on dementia towards the end of the book, in light of the rising incidence associated with age, and potentially being one of the biggest perceived risks to psychological wellbeing and mental ill-health. Interestingly, she discovers that subjective direct experiences throughout the lifecourse have more impact on a persons' mental health than their physical condition itself. She challenges the view that dementia is a mental illness where peoples' "management" is under psychiatric services and offers a different emphasis on the neurodegenerative condition and its potential relationship with mental health. A view that I share (depending on the type of dementia considered) as a dementia nurse specialist, having cared for people from diagnosis through to end of life and whose co-produced research with people living with the condition has explored. She goes on to champion the shifting perspectives in scholarship towards a social model of citizenship and personhood, resonating with the views of dementia activists who see their condition in terms of disability and where their human rights, autonomy, sense of self, meaning and purpose in life are respected (see 3 Nations Dementia Working Group, Dementia Engagement and Empowerment Programme). Her overarching argument that lifecourse experiences, personality and attitudes impact mental health also stand up when examining the dementia, quality of life and wellbeing literature. Here, studies indicate subjective quality of life in people who have dementia being more dependent on a person's premorbid ability to adapt and adjust and the extent of their social networks, relationships and environments, than on the condition itself.

Although Ageing in Later Life takes on the vastness of the subject, the scope of the book does not stretch to examine chronic severe mental illness or regard given to people living with learning disability or neurodiversity. As professor Milne points out herself that this in itself would require a text of the same breadth and complexity. The final chapter titled "Promotion and Prevention" is a hopeful move towards reviewing models and frameworks of ageing and mental health promotion. By asking the question how can good mental health be achieved in later life?, she draws from Marmot et al.'s (2010) recommendations of the need for 
International Journal of Ageing and Later Life

multi-agency involvement, where universal actions to reduce poverty, engage communities and provide targeted interventions are identified. I would like to go a step further and highlight the potential for involving the creative industries within these interventions, as evidence suggests the benefits of the arts and nature having a positive effect on mental health (Thomson et al. 2020).

Milne clearly shows her compassion and extensive experience as a practitioner, "real world" researcher and lecturer within the field of social gerontology who values and invites the voices of older people to inform. Although this critical review is aimed at academia, it is clearly accessible and a recommended resource for all professionals working within health and social care and policy, resulting in a highly readable, extensive review of the subject. As mentioned previously, many of the issues she raises have recently been exposed more widely in the media by the policies enforced due to the pandemic. I would recommend that all people working in policy, practice, research and academia will gain many insights and benefits from the wide angled lens of professor Milne's book.

\section{References}

Marmot, M., Allen, J., Goldblatt, P., Boyce, T., McNeish, D., Grady, M. \& Geddes, I. (2010). Fair society, healthy lives: Strategic review of health inequalities in England post 2010. London: University College London.

Suzman, R. M., Willis, D. P. \& Manton, K. G. (eds.). (1995). The Oldest Old. Oxford: Oxford University Press.

Thomson, L. J., Morse, N., Elsden, E. \& Chatterjee, H. J. (2020). Art, Nature and Mental Health: Assessing the biopsychosocial effects of a "creative green prescription" museum programme involving horticulture, artmaking and collections. Perspectives in Public Health 140(5): 277-285.

Velayudhan, L., Aarsland, D. \& Ballard, C. (2020). Mental health of people living with dementia in care homes during COVID-19 pandemic. International Psychogeriatrics, 32(10): 1253-1254. 